\title{
CAPACIDADE DE ESTADO DOS MUNICÍPIOS BAIANOS NA IMPLEMENTA ÇÃO DA POLÍTICA NACIONAL DE ASSISTÊNCIA SOCIAL (PNAS)
}

\author{
STATE CAPACITY OF BAHIAN COUNTIES IN THE IMPLEMENTATION \\ OF NATIONAL ASSISTANCE POLICY (PNAS)
}

\begin{abstract}
Resumo
Com quais capacidades municípios contam para agir com seu poder infraestrutural na implementação da Política Nacional de Assistência Social (PNAS) na Bahia? Esta é a pergunta de partida deste estudo que tem como objeto a implementação de uma política tardiamente regulamentada, se comparada às outras políticas sociais brasileiras, cujo objetivo é analisar a capacidade de Estado dos municípios baianos a partir de três dimensões - institucional, financeira e burocrática. Para tanto, foi realizada uma pesquisa exploratória-descritiva que toma o conceito de capacidade de Estado utilizado por Mann (1986) como seu referencial teórico. Metodologicamente, sua operacionalização se deu a partir da análise de variáveis quantitativas, oriundas de dados secundários, através de técnicas de sumarização de estatística descritiva utilizando medidas de posição. Como resultado final, argumenta-se que, apesar das limitações impostas a PNAS, houve progressivamente certa potencialização da capacidade de Estado dos municípios na institucionalização da política.
\end{abstract}

Palavras-chave: Capacidade de Estado. Implementação. Assistência social.

\begin{abstract}
With what capacities do counties count on to act with their infrastructural power in the implementation of the National Social Assistance Policy (PNAS) in Bahia? This is the starting point for this study, whose object is the implementation of a late policy when compared to other Brazilian social policies - and aims to analyze the state capacity of Bahia counties from three dimensions: institutional, financial and bureaucratic. For that, an exploratory-descriptive research was carried out that takes the concept of state capacity used by Mann (1986) as its theoretical reference. Methodologically, its operationalization was based on the analysis of quantitative variables, derived from secondary data, using descriptive statistical summarization techniques using position measurements. As a result, it is argued that, despite the limitations imposed on the PNAS, there was, progressively, a certain potentialization of the state capacity of cities in the institutionalization of politics.
\end{abstract}

Doutoranda pelo Núcleo de Pós-Graduação em Administração da Universidade Federal da Bahia (NPGA-UFBA).E-mail: sarafadigas@gmail.com. 
Keywords: State capacity. Implementation. Social assistance.

\section{INTRODUÇÃO}

Entre as políticas sociais no Brasil, a política de assistência social foi a última a finalizar seu processo de institucionalização, não acompanhando o mesmo timing de consolidação das outras políticas sociais. Para alguns autores, a razão desse atraso poderia se explicar pela opção por parte dos governos de um modelo de financiamento filantrópico, além da adoção de políticas de restrição de gasto presentes na década de 1980. (VAITSMAN; ANDRADE; FARIAS, 2009)

Apesar da institucionalização tardia da Política Nacional de Assistência Social (PNAS), seu gérmen inicial é contemporâneo ao de outras políticas sociais, já que na Constituição Federal de 1988 a assistência social foi elevada ao status de política pública integrante do Sistema de Seguridade Social brasileiro, junto à saúde e a previdência. Dessa forma, na Constituição a política de assistência social aparece como uma política não contributiva, destinada para aqueles que não conseguem suprir suas necessidades materiais, sociais e culturais pela renda do trabalho, ou por condição geracional - durante a infância ou a velhice -, ou ainda por necessidades físicas e/ou mentais. (MOTA, 2010)

Antes disso, as três primeiras grandes iniciativas no campo da assistência social no Brasil surgiram a partir da década de 1930. A primeira delas ocorreu em 1938 no governo de Getúlio Vargas, com a criação do Conselho Nacional de Serviço Social (CNSS), que se tornou no governo Itamar Franco o Conselho Nacional de Assistência Social (CNAS). A segunda iniciativa foi a criação da Legião Brasileira de Assistência (LBA) em 1942. Somente em 1977 houve a criação do Ministério da Previdência e Assistência Social (MPAS), ligado a Secretaria Nacional de Assistência Social (SNAS), assumindo as funções da antiga LBA. (PEREIRA, 2007)

O reconhecimento da assistência social como política pública efetivamente veio apenas em 1988 através de uma compreensão de que as ações ligadas à assistência social deveriam ser de responsabilidade direta do Estado, não apenas com ações residuais, mas de modo mais efetivo e sistemático. Contudo, levou ainda mais cinco anos para que houvesse a promulgação da Lei Orgânica da Assistência Social (LOAS) $n^{\circ}$ 8.742, em 1993, detalhando objetivos e diretrizes, e definindo as regras para a gestão da política.

A despeito da carta magna ser um marco na regulação da assistência social no Brasil do ponto de vista da definição de diretrizes de descentralização e participação, os avanços significativos na expansão da cobertura dos serviços apenas se concretizaram a partir do início do presente século. Desse modo, 
mais dez anos se passaram até que o último e decisivo marco para a assistência social ocorresse em 2003 durante a IV Conferência de Assistência Social com a deliberação da implantação do Sistema Único de Assistência Social (SUAS). O sistema seria elaborado de modo espelhado ao Sistema Único de Saúde (SUS) incorporando as diretrizes de participação e descentralização, além de deter fundo próprio de financiamento. A partir dos anos 2000 o sentido de governança da política é modificado ao possibilitar a formação de novas arenas e atores na formulação e implementação da política, além da criação de um sistema de proteção de caráter público e universal. (VAITSMAN; ANDRADE; FARIAS, 2009)

Tal sistema pretende ser um modelo de gestão participativa, articulando esforços e recursos nos três níveis de governo. A regulação do sistema veio a se efetivar em 2004, quando o CNAS aprovou a PNAS, coincidindo com a criação do Ministério do Desenvolvimento Social e Combate a Fome (MDS) - consolidada em 2005 por meio da Norma Operacional Básica do Suas (NOB/SUAS), a qual define as competências de cada ente federado e seus eixos de implementação e consolidação.

A partir de então foi possível observar a expansão da cobertura e dos benefícios do sistema, bem como o alargamento do escopo da proteção social no Brasil com os programas de transferência de renda. Ressalta-se, portanto, que as mudanças no campo da assistência social ocorreram a partir de uma ruptura paradigmática e conceitual, não apenas quanto à política, mas também de uma concepção maior acerca do papel do Estado na proteção social. (RIZZOTI, 2010)

A partir da NOB/SUAS de 2005 a Política Nacional de Assistência Social subdividiu-se em dois eixos: Proteção Social Básica (PSB) e Proteção Social Especial (PSE). A PSB é destinada à população em situação de vulnerabilidade social em decorrência da pobreza ou da privação e/ou fragilidade dos vínculos afetivos, relacionais e de pertencimento social, enquanto que a PSE tem por objetivo atender a famílias e indivíduos que estejam em situação de risco pessoal e social devido ao abandono, maus tratos, uso de substâncias psicoativas, cumprimentos de medidas socioeducativas, situação de rua, trabalho infantil, entre outras. (BRASIL, 2005)

O marco jurídico-institucional da política garantiu um sistema descentralizado, participativo e com coresponsabilidade de financiamento e gestão nas três esferas de governo: federal, estadual e municipal. A despeito das atribuições de cada ente federado, grosso modo, é possível afirmar que cabe à esfera federal formular e financiar a maior parte da política, enquanto é papel dos estados e municípios implementar e cofinanciar a política.

Assim, no que diz respeito à implementação da política, os municípios ficaram responsáveis por executar os projetos de enfrentamento à pobreza, incluindo a parceria com organizações da sociedade civil, atender às ações 
assistenciais de caráter de emergência, cofinanciar o aprimoramento da gestão, os serviços, os programas e os projetos de assistência social em âmbito local. Aos governos estaduais cabem prestar apoio técnico e financeiro aos municípios e ofertar serviços de proteção especial, cujos custos ou ausência de demanda municipal justifiquem uma rede social de serviços desconcentrada no âmbito do respectivo estado.

Sobre a PNAS é possível destacar diferentes visões no que diz respeito a institucionalização da política. Autores como Monnerat e Souza (2011) apontam limitações evidenciadas pela dificuldade que alguns municípios têm enfrentado até mesmo para aqueles que tiveram experiências exitosas na implantação de outras políticas sociais na criação dos Centros de Referência de Assistência Social (CRAS) e dos Centros de Referência Especializados de Assistência Social (Creas). Segundo os mesmos, isto resulta de uma tradição de frágil institucionalização da política juntamente à interveniência do clientelismo político persistente em nível local.

Por outro lado, outras pesquisas indicam progressos quanto ao SUAS e a implementação da PNAS no que diz respeito ao incremento da política e na redução da disparidade entre os municípios. (CAVALCANTE; RIBEIRO, 2012) Os autores indicam que a partir da criação do MDS o governo avançou no que diz respeito a institucionalização da assistência social ao promover a regulação estatal, a organização dos serviços com base em níveis de proteção, promover a intersetorialidade e distribuir as responsabilidades entre as esferas de governo. Já o trabalho de Andrade e Zimmermann (2011) sela uma visão nem tanto ao mar, nem tanto à terra. Para esses autores, houve inovações institucionais do SUAS com a operacionalização da PNAS como, por exemplo: a descentralização político-administrativa, a territorialização, a criação de um sistema de informações e a matricialidade sociofamiliar, muito embora tal operacionalização tenha sido acompanhada de tensões na mediação da prática da política.

Com quais capacidades os municípios baianos contam para agir com seu poder infraestrutural na implementação da Política Nacional de Assistência Social (PNAS)? Esta é a pergunta de partida que este estudo busca dar conta, cujo objetivo geral consiste em analisar a capacidade de Estado destes municípios a partir de três dimensões - institucional, financeira e burocrática. Embora haja estudos que explorem a implementação da PNAS no país, cabe ressaltar a importância desta pesquisa por realizar um recorte no estado da Bahia, sendo o único ou um dos poucos que realiza tal recorte.

Temporalmente a pesquisa circunscreve-se durante os sete primeiros anos de implementação da política a partir de sua regulamentação com a NOB/SUAS de 
2005. Por se tratar de um objeto ainda pouco explorado na literatura, metodologicamente caracteriza-se por um estudo exploratório e descritivo, operacionalizando sua análise a partir de variáveis quantitativas, oriundas de dados secundários, através de técnicas de sumarização de estatística descritiva utilizando medidas de posição.

A pesquisa ora apresentada traz os resultados de um mapeamento de indicadores de capacidade estatal destas três dimensões - infraestrutural, financeira e burocrática - de municípios baianos na implementação da PNAS, mais especificamente, o eixo da PSB num período que cobre os anos iniciais da institucionalização da política, a partir de 2005 , até o ano de 2012. A noção de capacidade aqui é compreendida a partir da dimensão do poder infraestrutural do conceito de capacidade de Estado de Mann (1986). De forma sintética, esse conceito pode ser apresentado como a capacidade que o governo tem de adentrar na sociedade e implementar logisticamente suas decisões políticas.

Este estudo apresenta indicadores que buscam compreender as capacidades dos municípios baianos do ponto de vista da sua infraestrutura da política, da conformação de suas burocracias envolvidas no processo de implementação e dos recursos financeiros, tomando como fonte principal dois bancos de dados, além de um índice produzido pelo MDS, o IDCRAS. ${ }^{2}$

O primeiro banco, a Pesquisa de Informações Básicas dos Municípios (Munic) 2005/2009 produzido pelo Instituto Brasileiro de Geografia e Estatística (IBGE) oferece dados do suplemento especial da função assistência social dos municípios. ${ }^{3}$ Trata-se de um banco de dados que agrega formulários de coleta autodeclarado pelos municípios e então repassado ao IBGE. A segunda base de dados foi produzido pelo MDS através do DATA Social, o Data SUAS, com informações referentes às unidades básicas que ofertam os serviços da PSB, os CRAS entre os anos de 2007 e 2012.

Este artigo encontra-se subdivido em quatro partes. A primeira, esta introdução, tem por objetivo sumarizar o histórico da construção da política de assistência social no Brasil, bem como apresentar o modo em que a política se organiza atualmente. Na segunda seção será discutido o conceito de Capacidade de Estado, referencial teórico da pesquisa, refletindo sobre sua pertinência

\footnotetext{
A partir do monitoramento dos CRAS feito pelo MDS, foi elaborado um índice com o objetivo de avaliar as características de funcionamento dos CRAS, os indicadores de desenvolvimento do CRAS (IDCRAS), constituído com quatro dimensões: recursos humanos, estrutura física, atividades realizadas e horário de funcionamento.

3 Embora haja uma série temporal da MUNIC para o ano de 2013, a incorporaçaõ do tipo de informação que essa base de dados disponibiliza não agrega tanto para a análise, visto que a politica não tende a regredir, tende a estabilizar.
} 
em estudos de análise de políticas públicas. Na seção três, que tem por objetivo operacionalizar a teoria, são apresentados os dados da PNAS referentes às dimensões infraestrutural (institucional), financeira e burocrática nos municípios baianos. Por fim, a última seção tece as considerações finais desse trabalho. É possivel ponderar logo de início que esta pesquisa realizou um esforço em mapear a implementação da política de assistência social durante os primeiros anos de implantação do SUAS nos municípios do estado da Bahia apontando resultados que indicam uma política que apesar das limitações, passou por um processo contínuo de capacidade de Estado dos municípios baianos.

\section{O CONCEITO DE CAPACIDADE DE ESTADO NOS ESTUDOS DE POLÍ- TICAS PÚBLICAS}

O conceito de capacidade de Estado desenvolvido por Mann (1986) foi utilizado em diferentes abordagens por autores como Skocpol (1979), Skocpol e Finegold (1982), Geddes (1994 apud SOUZA, 2010), entre outros autores. Capacidade de Estado é um conceito que busca compreender a relação de autonomia do Estado frente a sociedade através de duas dimensões analíticas - poder despótico e poder infraestrutural.

O poder despótico corresponde ao: "[...] espectro das ações que a elite estatal está capacitada a empreender sem a negociação de rotina, institucionalizada, com os grupos da sociedade civil". (MANN, 1986, apud DINIZ, 2001, p. 19). Já o poder infraestrutural consiste na capacidade em que o Estado tem de adentrar na sociedade e implementar logisticamente decisões políticas. A medida em que o Estado amplia seu poder "infraestrutural", ele consegue maximizar sua capacidade "despótica", se relacionando com a sociedade por meio da combinação entre essas duas dimensões de poder, resguardando sua centralidade e territorialidade. (MARTINS, 2008)

Como aponta Souza (2010), o estudo de Theda Skocpol e Kenneth Finegold (1982) é um exemplo de estudo de caso aplicado sobre o poder "infraestrutural" do Estado que analisa duas políticas norte-americanas do New Deal - a política industrial e a agrícola. Para os autores, a justificativa do sucesso ou insucesso da implementação destas políticas referentes a atividade econômica está assentada na organização administrativa do governo, uma vez que "[...] decisões tomadas pelos governantes nem sempre podem ser cumpridas e nem sempre os governos têm, ou podem mobilizar rapidamente, conhecimento, instituições e organizações capazes de implementar políticas por eles formuladas". (SOUZA, 2010, p. 3) 
Assim, podemos analisar a capacidade do Estado a partir da existência ou inexistência de alguns fatores: políticos, institucionais administrativos e técnicos. Para checar a presença ou não desses fatores, variáveis de diferentes naturezas podem ser analisadas, entre elas: recursos financeiros, infraestrutura, informacional, desenho das políticas e suas regras, tamanho e qualidade da burocracia, maioria em bancada legislativa, conciliação da política pública com interesses privados, políticas prévias, informações sobre políticas semelhantes (policy learning) e alcance territorial.

Podem também ser incorporadas a análise da capacidade de Estado variáveis mais qualitativas, como autonomia política, legitimidade e coerência interna. (SOUZA, 2010) Cingolani (2013) realiza uma revisão de literatura mais atual sobre o conceito e aponta que o fato do conceito ser aparentemente de fácil compreensão pelo senso comum passa a impressão de que pode ser apropriado sem grandes dificuldades em pesquisas, por essa razão, as dificuldades em mensurá-lo representam o desafio mais importante para as pesquisas que pretendem utilizá-lo.

Partindo do suposto de que o Estado necessita agir com seu poder infraestrutural para então adentrar na sociedade, importa empreender ações que visem a esses objetivos. Tais ações podem ser identificadas em investimentos focalizados: a) em sua infraestrutura, tanto no que diz respeito a sua regulamentação quanto a sua efetivação; b) em sua burocracia, no que versa aos investimentos em gestão e profissionalização e, por fim c) dotar o aparelho do Estado com investimentos em recursos financeiros para a implementação de suas políticas.

Logo, quando tratamos aqui do conceito de capacidade de Estado, estamos nos referindo à dimensão do poder infraestrutural do Estado. A seção seguinte analisa as capacidades de Estado dos governos municipais no estado da Bahia quanto à implementação da Política de Assistência Social do ponto de vista de três dimensões: capacidade institucional; capacidade burocrática e capacidade financeira. Contudo, diferentemente dos trabalhos citados os quais se referem ao governo federal, o enfoque deste trabalho recai sob a capacidade dos governos municipais. 


\section{CAPACIDADES INFRAESTRUTURAL, FINANCEIRA E BUROCRÁTICA DOS MUNICÍPIOS BAIANOS}

Esta terceira seção operacionaliza os conceitos apresentados na seção anterior. Para tanto, discute os resultados da pesquisa articulando as dimensões do conceito de Capacidade de Estado - dimensão infraestrutural (institucional), financeira e burocrática - com dados da assistência social nos municípios da Bahia disponíveis em duas bases de dados: a Munic e o Data SOCIAL - Data SUAS.

Do ponto de vista da dimensão infra-estrutural (institucional) é possível afirmar um processo de consolidação da assistência social no Estado, embora os dados apresentem ainda um número aquém de CRAS efetivamente implementados. Na dimensão financeira, os resultados apontaram para um investimento tímido na área, porém que vem sendo incrementando, com destaque para o governo federal. Por fim, da perspectiva da capacidade burocrática os dados indicaram que há uma fragilidade nos vínculos, sobretudo para aqueles burocratas de linha, implementadores da política no nível de rua, enquanto que aqueles burocratas alocados diretamente nas secretarias apresentaram melhoras em sua capacitação profissional.

\section{CAPACIDADE INFRAESTRUTURAL (INSTITUCIONAL)}

O primeiro eixo analisado dá conta da regulamentação, institucionalização e da situação estrutural da PNAS nos municípios baianos. As variáveis selecionadas tratam do estágio de institucionalização da política de assistência social a partir da presença ou não de regras que garantam sua efetivação, conforme proposto pela NOB/SUAS, bem como da existência das instituições que permitam a estruturação da política para que a mesma chegue até o beneficiário.

Os primeiros dados analisados tratam dos indicadores da regulamentação da assistência social nos anos de 2005 e 2009, quais sejam: a) Se a Lei Orgânica do município trata da assistência social; b) existência de definição legal de percentual do orçamento do município para a assistência social; c) regulamentação do Conselho Municipal; d) regulamentação do Fundo Municipal; e) regulamentação da Política Municipal; f) dos projetos, programas e ações.

O cenário indicado mostra uma política que em alguns aspectos já se encontrava, desde 2005 , consolidada do ponto de vista de sua regulamentação - uma vez que quase a totalidade dos municípios, afirmavam que a função assistência social já se encontrava presente na Lei Orgânica do município, além de já contarem com conselhos e fundos regulamentados. 
Apesar do aspecto da produção legislativa ser importante para a análise da institucionalização de uma política, pouco adiantará se o que está presente na lei não se tornar efetivo. Por isso, além das variáveis de regulação, coube também identificar variáveis que dessem conta de ilustrar o que de fato foi implantado a partir da lei. Sobre a existência dos Fundos e Conselhos municipais, os resultados são idênticos aos de sua regulamentação, tanto para os anos de 2005 como para 2009, conforme constam no Gráfico 1.

Destacamos ainda a presença de Plano Municipal - em 2005, cerca de $87 \%$ dos municípios declararam ter o plano, enquanto em 2009 esse número alcança $93 \%$ dos municípios, além das variáveis ligadas ao fundo de assistência social. É possível destacar ainda que há conselhos e planos sem haver fundo, indicando que a dotação orçamentária, ou melhor, a falta desta dotação, constrange a implementação da política.

Quanto a natureza do conselho, as informações indicam um recuo no número de municípios que afirmaram ter conselho deliberativo entre os anos de 2005 e 2009. Apesar desse recuo, há que se considerar não raramente encontramos certas imprecisões nos dados da Munic, o que pode talvez ser explicado devido a forma de coleta desses dados através do autopreenchimento das prefeituras. Caso confirmado este dado na realidade, este pode ser um alerta para a necessidade de uma análise mais detalhada, visto que podemos considerar esta variável como uma proxy de participação, prerrogativa básica da PNAS.

Gráfico 1 - Porcentagem da distribuição das variáveis institucionais da assistência social nos municípios da Bahia em 2005 e 2009

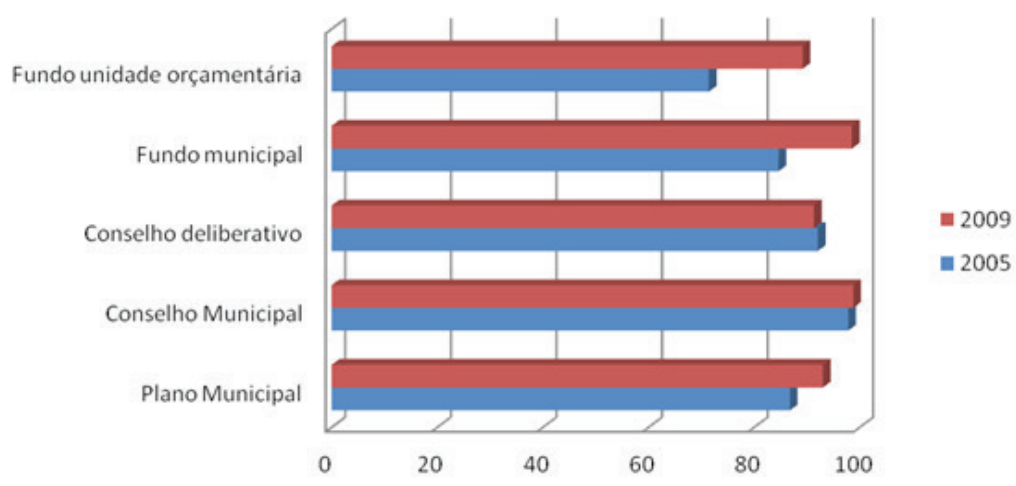

Fonte: adaptado de Instituto Brasileiro de Geografia e Estatística (2005, 2009).

Um termômetro valioso para observar de que maneira o SUAS tem se capilarizado no estado da Bahia é a variável que traz a informação sobre a evolução da implantação dos CRAS nos municípios. Estes aparelhos são encarregados de garantir o direito sócio-assistencial de acesso aos serviços da PSB, concretizados 
em espaços físicos localizados estrategicamente em áreas de maior pobreza para atender a indivíduos em situação de vulnerabilidade e risco social. A despeito de sua matricialidade familiar - e por isso uma designação comum é o termo "Casas da Família" - os CRAS atendem também grupos e indivíduos em situação de vulnerabilidade social. Funcionam como a unidade efetivadora de inserção dos indivíduos assistidos ao SUAS, bem como, garantem o acesso às demais políticas públicas, agindo como "porta de entrada" de uma série de serviços.

O principal programa oferecido pelo CRAS é o Programa de Atenção Integral à Família (PAIF) (Decreto Federal n ${ }^{\circ}$ 5.085/04). O programa agrega um conjunto de ações de acolhida, informação e orientação sobre assistência social, além de conduzir a inserção em serviços da assistência social, tais como serviços sócio-educativos e de convivência, encaminhamento para outras políticas, a promoção de acesso à renda e, sobretudo, acompanhamento sócio-familiar. Todas essas atividades são executadas por um grupo multidisciplinar denominado "equipe de referência do CRAS" composta por psicólogos, assistentes sociais, atendentes administrativos e profissionais de outras áreas. Os objetivos visados por este programa são de prevenção e enfrentamento em situações de vulnerabilidade e risco social, fortalecimento dos vínculos familiares e comunitários e promoção de aquisições sociais e materiais às famílias, ressaltando o protagonismo e autonomia das famílias e comunidades.

Cabe aos municípios identificar os territórios de vulnerabilidade para a implantação do CRAS cujos critérios são definidos pela NOB/SUAS, apontando para questões relacionadas a precariedade de infraestrutura, presença de crianças, adolescentes, idosos e pessoas com deficiência em famílias com renda de até meio salário mínimo ou ainda, famílias em situação de trabalho infantil ou com presença de crianças e adolescentes em idade escolar fora da escola, além de outras questões.

Na Bahia, houve uma crescente evolução na implantação dos CRAS nos municípios baianos entre os anos de 2007 e 2012, com uma média de 40 novas unidades abertas a cada ano. Em 2007 havia 339 unidades, enquanto que em 2012 esse número subiu para 579, representando um aumento de 240 novos centros implantados durante o período analisado no gráfico, o que significa que já neste ano havia alguns municípios que contavam com mais de um CRAS.

Levar em conta as observações produzidas a partir do IDCRAS - que leva em conta as variáveis de recursos humanos, estrutura física, atividades realizadas e horário de funcionamento - é de fundamental importância para a análise da implementação da política de assistência social, pois oferece um retrato mais próximo da situação do SUAS nos municípios. Em 2013, o IDCRAS médio para 
os municípios baianos foi de 0,68 , juntamente com os municípios do estado de Goiás, posicionando-os na $8^{\circ}$ colocação entre os melhores estados brasileiros. O Gráfico 2 mostra a distribuição do valor do IDCRAS sintético de todos os CRAS dos municípios baianos entre os anos de 2011 e 2012, apontando um crescimento significativo dos municípios que alcançaram a nota máxima na escala do índice (9), passando de $141 \mathrm{em} 2011$ para $264 \mathrm{em}$ apenas um ano. Cabe ressaltar também que ainda no ano de 2012 nem todos os municípios baianos contavam com a presença de um CRAS.

Gráfico 2 - Distribuição de CRAS por índice do IDCRAS em municípios da Bahia (2011 e 2012)

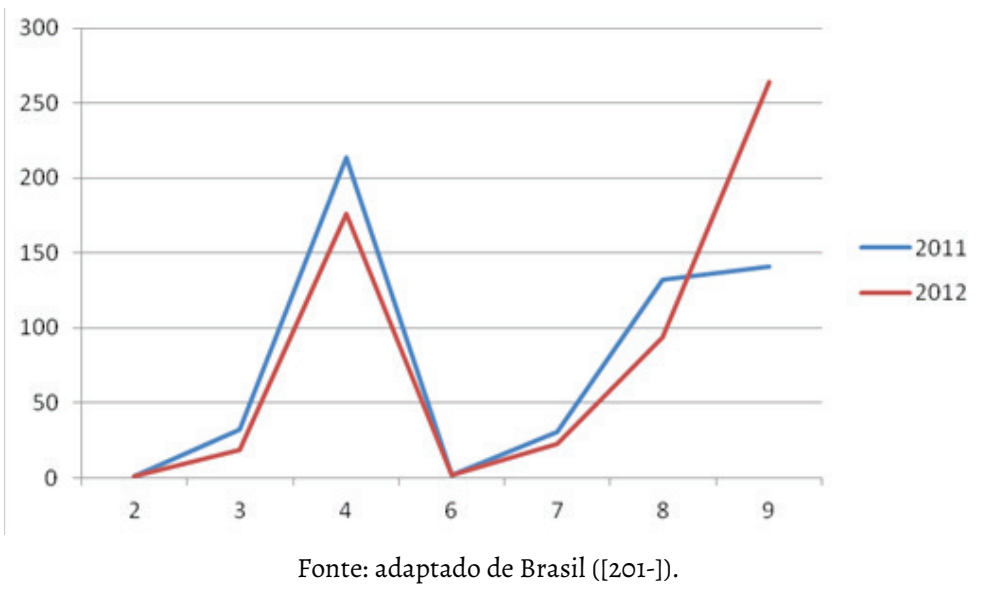

Para as variáveis institucionais pode-se inferir que há um processo que vem se consolidando. Entretanto, quando conjugamos os dados das variáveis reguladoras e institucionais com o número de centros de referências efetivamente implementados percebemos que ainda há um descompasso na implementação da política, condição que adverte para a necessidade de um aprofundamento da análise.

\section{CAPACIDADE FINANCEIRA}

A arrecadação, distribuição e aplicação dos recursos necessários para a execução da PNAS é realizado de forma descentralizada, com recursos oriundos dos orçamentos da união PNAS, dos estados e municípios. Assim, estados e municípios também alocam em seus orçamentos recursos através de Fundos Estaduais e Municipais de Assistência Social. O cofinanciamento com base na divisão de competências por cada ente federado é definido seguindo critérios da política como porte, complexidade dos serviços e diversidades regionais. 
No âmbito federal, o financiamento dos programas geridos pelo Ministério provém de recursos orçamentários próprios ou do Fundo Nacional de Assistência Social (FNAS). ${ }^{4} \mathrm{O}$ cofinanciamento da PNAS com recursos federais do fundo garante grande parte dos recursos de programas de PSB, PSE e dos Programas de Erradicação do Trabalho Infantil (PETI), de combate ao abuso e à exploração sexual de crianças e adolescentes e de economia solidária em desenvolvimento. O cofinanciamento pelo FNAS segue uma distinção básica entre as políticas de caráter continuado, realizando transferências regulares e automáticas e outra para as políticas de caráter especial, com recursos que chegam através de convênios e contratos de repasse. Desse modo os programas oferecidos pelos CRAS, por serem de PSB, tem o repasse dos recursos disponibilizados fundo a fundo.

O FNAS tem na figura do MDS seu gestor, realizando suas atividades sob orientação, acompanhamento e fiscalização do CNAS. O procedimento para os fundos estaduais e municipais é similar. Estes são geridos pelos órgãos responsáveis pela assistência social nessas esferas de governo, também sob orientação e fiscalização dos respectivos conselhos estaduais e municipais de assistência social, a fim de que se cumpra a diretriz constitucional da participação, uma das demandas dos sistemas democráticos consolidados, que supõe o controle social de políticos e burocratas.

O Fundo Estadual de Assistência Social (FEAS) é a instância estadual responsável por arcar com as despesas da PNAS neste nível de governo e repassar valores para os municípios. Este é um dos fundos que garantem recursos para o provimento da política nos estados sendo diretamente gerido pela secretaria estadual de assistência social. Além de ter recursos próprios provenientes da receita dos estados, recebe recursos vindos do FNAS - dividindo esses repasses com os fundos municipais de assistência social. Os programas contemplados com recursos desses fundos são aqueles que prestam serviços continuados, portanto, os CRAS contam com os recursos desse fundo para o provimento de seus programas e serviços.

Em nível local, os municípios devem se ocupar desde a regulamentação da política através da inclusão do tema na LOAS, até a implantação dos aparelhos centrais da PNAS - os CRAS. De acordo com a prescrição da NOB/SUAS 2005, para que um município possa habilitar-se em qualquer um dos níveis de

\footnotetext{
As receitas do FNAS são provenientes de recursos da União, eventuais doações de pessoas jurídicas ou pessoas físicas, contribuição social dos empregadores, recursos vindos de concursos, sorteios e loterias, no âmbito do Governo Federal, receitas de aplicações financeiras de recursos do Fundo, receitas da alienação de bens móveis da União, bem como de transferências de outros fundos.
} 
gestão do SUAS é necessária a criação, além de Conselho e Plano municipal, do Fundo Municipal de Assistência Social (FMAS). Assim como no caso do FEAS, os recursos do FMAS tem origem do FNAS, através de transferências constitucionais, sem interferência do governo estadual, além de recursos próprios investidos pelos municípios. Como não há um piso básico pré-definido, os municípios tem independência para decidir quanto de investimento próprio será destinado ao seu fundo.

Nosso segundo eixo de análise - capacidade financeira - leva em conta os gastos com assistência social. Para ter uma visão destes gastos por cada ente - união, estados e municípios - usaremos indicadores que contenham valores investidos por cada uma dessas esferas, para tanto utilizaremos nos Gráficos 03 e 04 da classificação dos portes dos municípios na habilitação do SUAS, que dizem respeito a exigência mínima da quantidade de CRAS por município por quantidade de habitante. Nos municípios de pequeno porte I e pequeno porte II, exige-se apenas a existência de um CRAS em funcionamento, para os de médio porte II, os de grande porte IV e para as metrópoles VIII. Na Bahia há uma maior concentração dos municípios de pequeno porte (I e II), somando pouco mais de $90 \%$. O médio porte registra $6,5 \%$ e grande porte, 3,6\% dos municípios, por fim, apenas Salvador atende ao porte de metrópole.

No Gráfico 3, a variável analisada remete aos gastos municipais com a função assistência social no ano de 2005, primeiro ano de política institucionalizada. Trata-se, portanto, do valor total previsto dos recursos próprios do município para esta área. Como é possível observar para este ano, os recursos municipais estavam mais concentrados nos municípios de pequeno porte II (quase R\$ 100 milhões), apesar de a maior concentração de municípios na Bahia pertencer ao pequeno porte I (248 municípios nestes e 126 naqueles). Analisando ainda esta variável a partir de sua média, ou seja, dividindo o gasto total do porte pela quantidade de municípios que a ele pertence, observamos que as prefeituras de porte médio são as que relativamente investem menos na área. Estas, comparadas às prefeituras de pequeno porte II, por exemplo, tem um gasto médio de cerca de 2 milhões a menos. 
Gráfico 3 - Valor previsto dos recursos próprios do município destinados à Assistência Social nos municípios da Bahia por porte do CRAS em reais (2005)

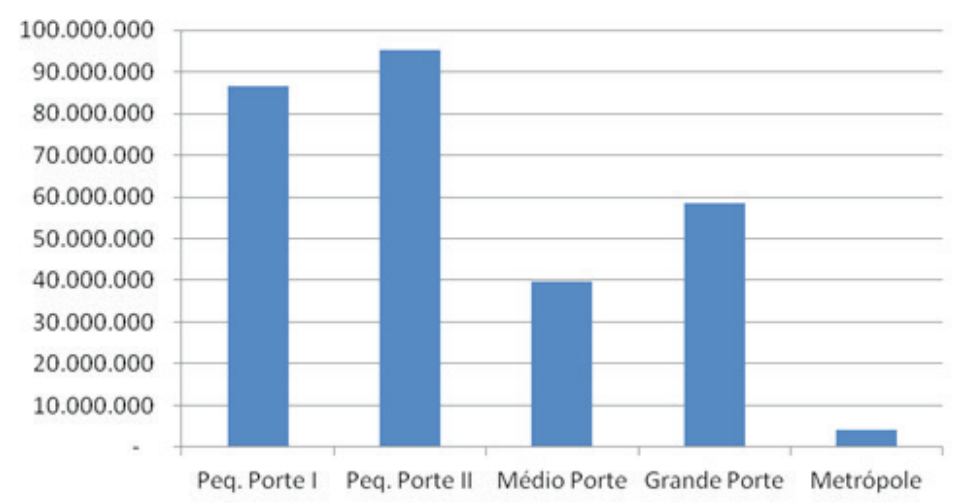

Fonte: adaptado de Instituto Brasileiro de Geografia e Estatística (2005).

O Gráfico 4 apresenta o cofinanciamento da política entre as esferas federal e estadual. O cofinanciamento estadual tem como critério diagnósticos socioterritoriais, levando em conta duas dimensões: a) o porte populacional do município para o CRAS que definirá a porcentagem de recursos que receberá e b) o índice de vulnerabilidade municipal composto, que definirá a hierarquização dos municípios para o cofinanciamento. ${ }^{5}$

A diferença no valor médio de investimento dos recursos entre os dois níveis de governo é significativa. O montante de recursos investidos pela união é muito superior se comparado ao investido pelo governo estadual. Com exceção do município de porte de metrópole, que apresenta um pouco mais de $20 \%$ dos recursos investidos naquele município advindos do governo estadual, a variação entre os outros grupos de municípios é muito pequena. Podemos inferir que os recursos de cofinanciamento são majoritariamente destinados pela união e o governo estadual investe mais no município que tem o porte de metrópole (Salvador), e em seguida, nos municípios de pequeno porte II vis-à-vis aos municípios agregados em outros portes.

A elaboração do índice de vulnerabilidade municipal composto leva em conta quatro indicadores: a) a taxa de vulnerabilidade social do município; b) taxa de mortalidade; c) taxa de natalidade e d) receita corrente líquida per capita. 
Gráfico 4 - Proporção do valor médio de cofinanciamento federal e estadual nos municípios da Bahia por porte do CRAS em 2009

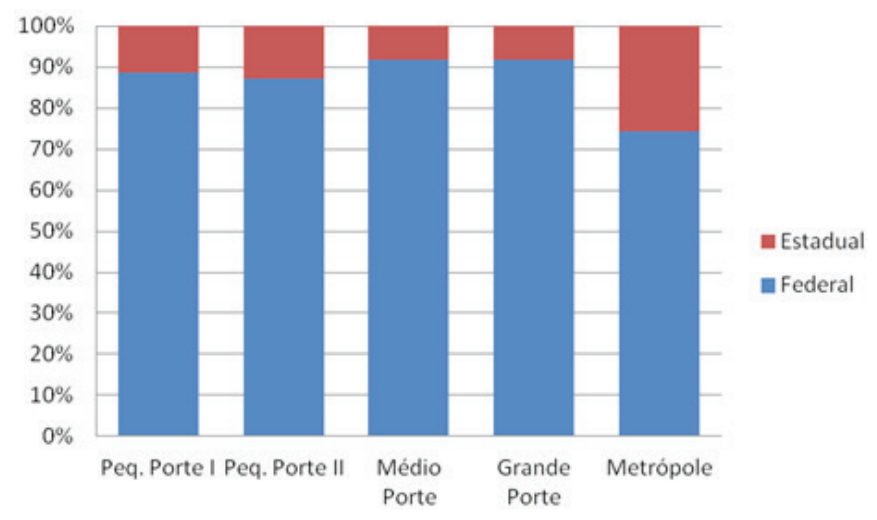

Fonte: adaptado de Instituto Brasileiro de Geografia E Estatística (2009).

O Gráfico 5 exibe a origem do financiamento dos CRAS por ente federerado nos municípios baianos ao longo do período entre 2007 e 2012 . No primeiro ano a política foi primordialmente financiada pela União e pelos municípios, para em seguida, ser de responsabilidade da União, exclusivamente. Com o passar dos anos esse quadro foi aos poucos sendo revertido, quando a partir de 2009 passou a vingar mais vigorosamente um financiamento dos três níveis federados, conforme é previsto no texto da política.

O elevado número de CRAS financiado pelos três níveis de governo sinaliza o processo de institucionalização da política, vez que o governo federal efetivamente induz os outros dois níveis de governo a se responsabilizarem financeiramente. O que converge com resultados apontados por Cavalcante e Ribeiro (2012) que sugerem que ocorreu uma indução à cooperação fundamentada em uma estrutura de incentivos e constrangimentos, ao passo que fomentou a participação dos governos subnacionais através de processo de negociação e adesão voluntária. Quanto ao financiamento exclusivo de um nível de governo, o governo federal é o que mais se destaca, com exceção do ano de 2011, em que o peso exclusivo recaiu para os municípios, já o governo estadual apresenta um tímido financiamento exclusivo do que se comparado às outras duas esferas. 
Gráfico 5 - Quantidade de CRAS por fonte de financiamento

nos municípios da Bahia entre os anos de 2007 e 2012

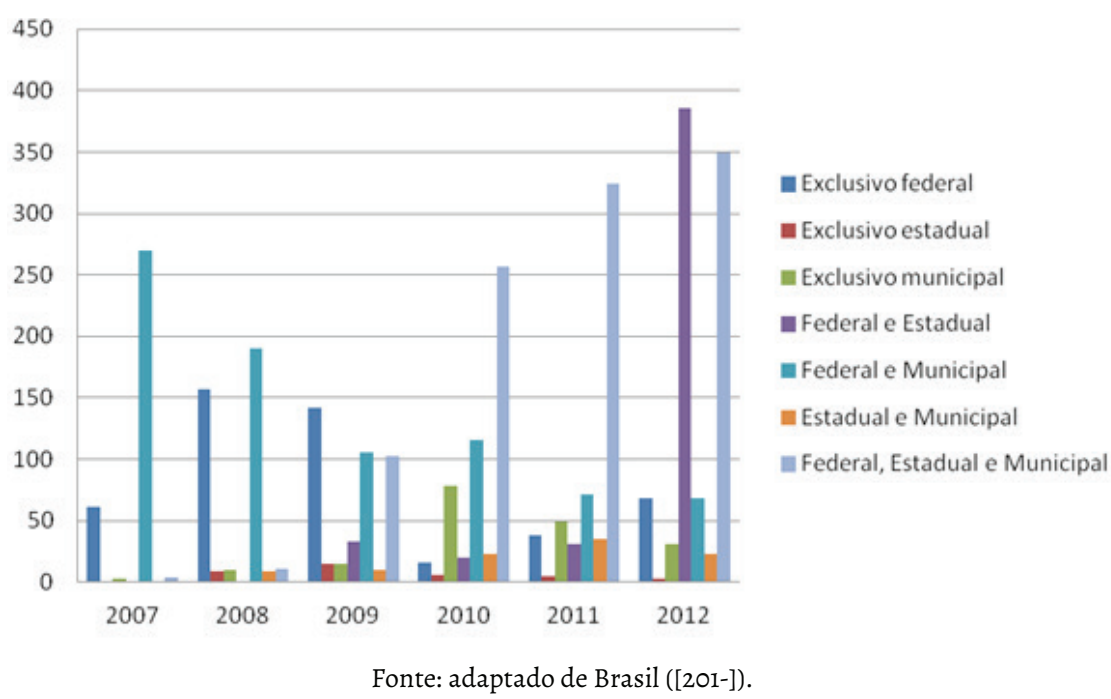

CAPACIDADE BUROCRÁTICA

A terceira dimensão tenta dar conta do tamanho e da profissionalização da burocracia, agente importante nos processos de implementação de políticas públicas. De acordo com Sátyro, Cunha e Campos (2016) por ser a política de assistência realizada através da oferta de serviços nos municípios há uma grande dependência desta da burocracia implementadora. Interessa também saber critérios de recrutamento dessa burocracia, se atendeu ao mérito e competitividade ou se atende a critérios outros, não prioritários no desenho da política. ${ }^{6}$

Ainda conforme Sátyro, Cunha e Campos (2016), a maioria dos estudos sobre burocracia no Brasil tendem a enfocar o nível federal de gestão, porém, o processo de descentralização pelo qual o país passou a partir da Constituição de 1988 requer a necessidade de estudos que enfoquem o nível municipal de governo, posto que pouco se sabe sobre a configuração dessas burocracias e menos ainda sobre sua capacidade de ação.

O Gráfico 6 estabelece uma relação entre a quantidade de funcionários ocupados na assistência social dos municípios e o tipo de vínculo empregatício

\footnotetext{
Quanto a este último aspecto, se a burocracia é formada por critérios políticos, a investigação através dos dados quantitativos pode não dar resultados seguros. Contudo, é possível utilizar os dados de cargos comissionados como uma proxy de critério político. Lembrando que para essa proxy ser mais válida é preciso levar em conta também o grau de instrução dos membros da burocracia, visto que cargos comissionados muitas vezes são justificados por competência técnica. Tem-se clareza da necessidade de uma discussão mais substantiva sobre os dados presentes neste gráfico.
} 
nos anos de 2005 e 2009. É notável o crescimento da burocracia para todas as categorias de vínculo empregatício, com exceção apenas do vínculo de celetista que decresce 469 cargos em 2009 em relação a 2005, e dos estagiários, que apesar de não decrescer, apresenta um crescimento tímido. Contudo, o grande destaque é para os funcionários sem vínculo empregatício, que crescem $44 \%$ no ano de 2009 com relação ao ano de 2005 , o que equivale a 2.557 cargos criados, ao passo que os funcionários estatutários cresceram apenas 15\% nestes anos.

Apesar do crescimento do tamanho de sua burocracia, o tipo de vínculo empregatício priorizado não é o estatutário, mas aqueles de caráter mais instável. Quanto aos cargos comissionados, indicados em nota como proxy de critérios políticos na formação da burocracia, estes registram um crescimento de $31,5 \%$. Conforme alertado também em nota, para que essa evidência ganhe maior consistência é necessário que se observe não só o vínculo empregatício, mas também o grau de instrução dessa burocracia.

Deve ser levado em conta se esse acréscimo abrupto do total de pessoal ocupado na assistência social pode não ser motivado exclusivamente por critérios universalistas, mas antes por uma prática clientelista de oferta de cargo público como moeda de troca política. Para que seja possível investigar isso, é necessário observar não apenas o tamanho da burocracia, mas também a qualidade.

Gráfico 6 - Pessoal ocupado na burocracia da assistência social dos municípios por vínculo empregatício na Bahia em 2005 e 2009

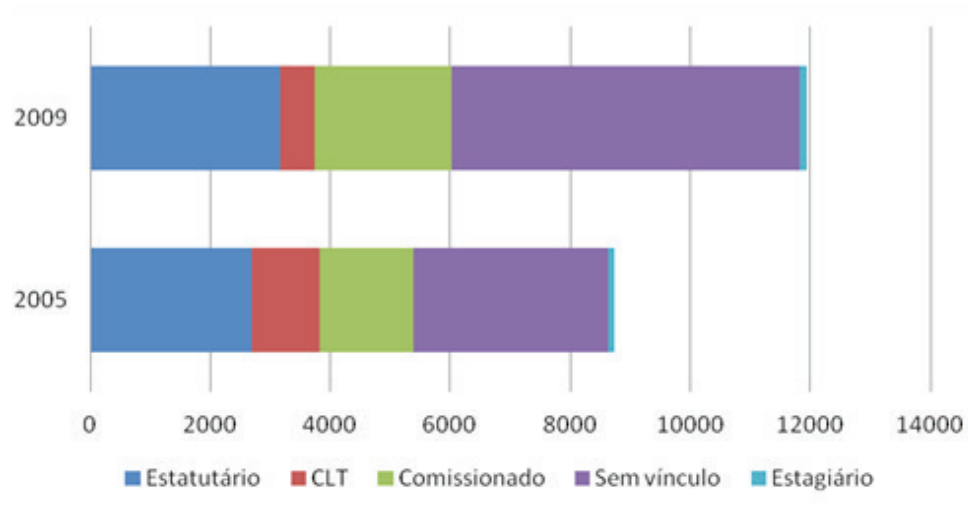

Fonte: adaptado de Instituto Brasileiro de Geografia e Estatística (2005, 2009).

Salta aos olhos o fato de que a burocracia implementadora da política no estado é predominantemente formada por nível médio de escolaridade, e que de uma forma geral não houve avanço entre 2005 e 2009 para todos os tipos de vínculo empregatício. Se somados, portanto, as burocracias especializadas - com nível superior e pós-graduação - representam uma minoria do quadro 
técnico. Analisando o grau de instrução dos funcionários comissionados, observamos, tanto em 2005 quanto em 2009, ser este o vínculo empregatício que abriga maior concentração de funcionários nos dois níveis de instrução mais elevados - graduação e pós-graduação. Contrariando, portanto, uma expectativa de que cargos comissionados não seguiriam critérios meritocráticos ou técnicos em seu preenchimento.

Os dados mostram que houve uma maior profissionalização da burocracia, vez que para todos os tipos de vínculo, o número de funcionários apenas com formação em ensino fundamental diminui, ao passo que funcionários com nível superior e pós-graduações tiveram um incremento, como por exemplo os funcionários estatutários que em 2005 registravam 9,7\% de funcionários com ensino superior e passaram a 13,5\% em 2009.

Podemos caminhar mais à ponta do processo e analisar a equipe técnica de referência empregada nos CRAS. Segundo dados do Data SUAS, em seis anos de política - entre 2007 e 2012 - a Bahia teve um incremento de $66 \%$ de funcionários trabalhando na linha de frente da PSB, com uma média anual de crescimento de 520 contratados por ano durante esse período. O Gráfico 7 mostra dados referentes ao tipo de vínculo que esses funcionários estabelecem com as secretarias de assistência municipal. Fica visível que o vínculo predominante para esses trabalhadores - sem vínculo permanente - é o mais precário entre todos os possíveis, além de vir crescendo de maneira desproporcional ao longo desses seis anos, sobretudo se comparado aos outros tipos de vínculo.

Essas informações sugerem controle sobre a contratação da burocracia municipal por parte do órgão gestor do município indicando ausência de contratos mais estáveis para os trabalhadores, condição que constrange imprimir um sentido de continuidade à implementação da política. Apesar de tímido, cabe ressaltar o quantitativo dos funcionários estatutários, que aparece como o segundo predominante, ainda que muito abaixo do primeiro, ultrapassando cargos comissionados e vínculos de Consolidação das Leis do Trabalho (CLT). 
Gráfico 7 - Funcionários empregados nos CRAS nos municípios

da Bahia por vínculo empregatício entre 2007 e 2012

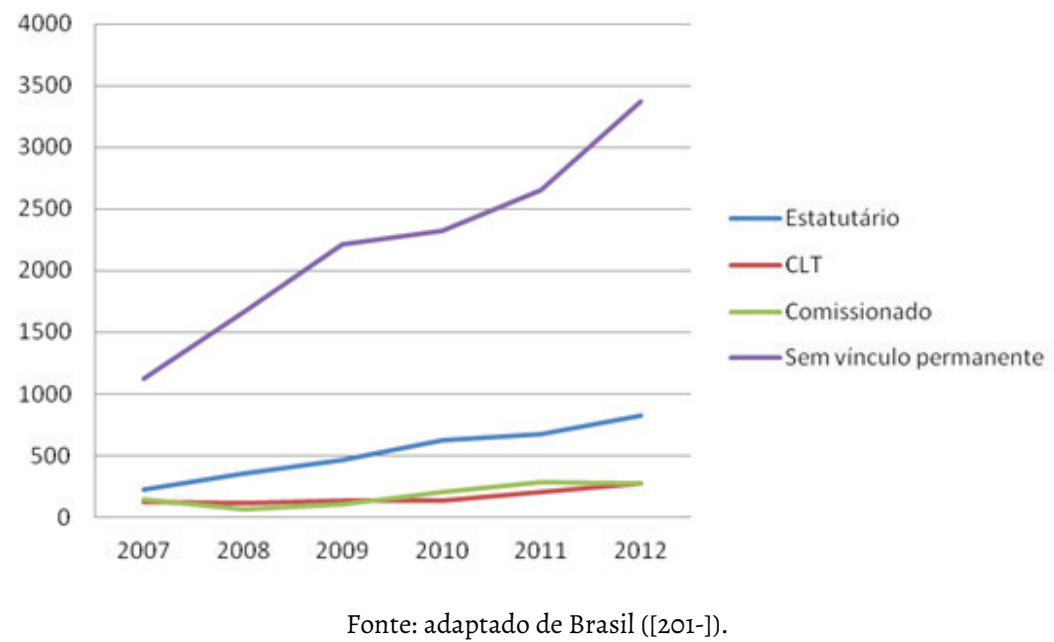

Por fim, ainda sobre o eixo capacidade da burocracia, examinaremos variáveis que tratam do órgão político responsável pela gestão da assistência social no município. Em 2009, quando perguntados, através do questionário da MUNIC, se o gestor da política era a primeira dama, 97 municípios, ou seja, cerca de $23 \%$ dos municípios baianos, responderam afirmativamente. ${ }^{7} \mathrm{~A}$ Tabela 1 mostra a distribuição do grau de instrução do responsável pelo órgão gestor nos anos de 2005 e 2009 nos municípios baianos. Assim como a situação dos ocupados na burocracia assistencial nos mostrou um panorama de maior profissionalização com o crescente número das faixas mais instruídas, o mesmo podemos dizer para o caso do gestor assistencial. Aqui, tal como lá, as faixas menos instruídas - de fundamental incompleto a médio completo - apresentam queda entre os anos de 2005 e 2009 e, a partir do superior incompleto, os números começam a subir. É expressivo ainda o percentual de gestores que possuem pós-graduação em 2009 (cerca de 17\%).

Tabela 1 - Total e frequência dos gestores da assistência social por grau de instrução nos municípios da Bahia em 2005/09

\begin{tabular}{l|c|c|c|c}
\hline \multirow{2}{*}{ Grau de instrução } & \multicolumn{2}{|c|}{2005} & \multicolumn{2}{c}{2009} \\
\cline { 2 - 5 } & Total & Freq. & Total & Freq. \\
\hline Fundamental incompleto & 11 & $3 \%$ & 3 & $1 \%$ \\
\hline Fundamental completo & 13 & $3 \%$ & 6 & $1 \%$ \\
\hline
\end{tabular}

O chamado primeiro-damismo na assistência social é um fenômeno recorrente na história da assistência social brasileira. Está, em geral, muito ligado a uma noção assistencialista da proteção social e atribuída a uma visão pouco institucionalizada da política. 


\begin{tabular}{l|c|c|c|c}
\hline Médio incompleto & 15 & $4 \%$ & 12 & $3 \%$ \\
\hline Médio completo & 159 & $38 \%$ & 101 & $24 \%$ \\
\hline Superior incompleto & 80 & $19 \%$ & 82 & $20 \%$ \\
\hline Superior completo & 105 & $25 \%$ & 142 & $34 \%$ \\
\hline Pós-Graduação & 34 & $8 \%$ & 70 & $17 \%$ \\
\hline Não aplicável & - & - & 1 & $0 \%$ \\
\hline Total & 417 & 100.00 & 417 & 100.00 \\
\hline Fonte: adaptado de Instituto Brasileiro de Geografia e Estatística (2005, 2009).
\end{tabular}

Fonte: adaptado de Instituto Brasileiro de Geografia e Estatística $(2005,2009)$.

\section{CONSIDERAÇÕES FINAIS}

Esse trabalho realizou um esforço em mapear indicadores de implementação da política de assistência social durante os primeiros anos de implantação do SUAS, abrangendo o universo dos municípios do estado da Bahia. Para tanto, se empenhou em responder com quais recursos os municípios contam para a implementação da política de assistência social e como essa política tem sido implementada. Os dados foram coletados no sentido de abranger três dimensões da capacidade de Estado - infraestrutural, financeira e burocrática. Do ponto de vista da institucionalização da PNAS, o que este trabalho demonstrou foi o fortalecimento da estrutura que garante sua efetivação, na medida em que é possível perceber um movimento crescente da regulamentação e formação de conselhos, fundos e planos municipais, bem como, da implantação dos CRAS.

Do ponto de vista da capacidade financeira, apesar da assistência social contar ainda com um investimento tímido, os dados demonstraram um incremento por parte dos entes federados nos aportes dessa política. Contudo, o governo federal ainda se encontra em posição de destaque, seja como principal financiador, ou como um ente com poderes de indução para que os níveis subnacionais ampliem os gastos com essa área. Além disso, o fato de grande parte dos recursos ter origem federal indica que há pouca mediação regional e a política se apresenta de forma pulverizada e residual nos municípios, indicando uma possível sensibilidade aos ciclos eleitorais.

Quanto à capacidade burocrática, evidencia-se a fragilidade dos tipos de vínculos nessa área, sobretudo nos burocratas de linha, que se encontram nos CRAS implementando diretamente a política. Contudo, no que diz respeito à burocracia ligada às secretarias de assistência social, entre os anos de $2005 \mathrm{e}$ 2009, chama atenção melhorias de sua capacitação, mesmo para aqueles que detém cargos comissionados.

Em que pese as limitações de dados da MUNIC como a incerteza da fidedignidade devido ao autopreenchimento pelos órgãos municipais, bem como, 
limitações do próprio tempo de maturação da política que ainda é muito recente, dificultando a possibilidade de realizar inferências mais abrangentes, é possível afirmar que há evidências que apontam para uma institucionalização da política de assistência social nos municípios baianos. Desse modo, os dados do Data SUAS complementaram a análise, por oferecerem uma sequência constante de seis anos de implementação da política no que se refere aos CRAS. Esses últimos apontaram, entre outros elementos, a expansão dos CRAS nos municípios baianos e uma melhora no IDCRAS. Assim, ainda que se faça todas as necessárias ressalvas acerca das limitações que a política encontra, é possível apontar que houve de modo progressivo certa potencialização da capacidade do Estado dos municípios baianos em implementar a PNAS.

\section{REFERÊNCIAS}

ANDRADE, F. F.; ZIMMERMANN, C. R. A institucionalização da assistência social: a implantação do SUAS no norte do estado de Minas Gerais. Acta Scientiarum. Human and Social Sciences, Maringá, v. 33, n. 2, p. 129-137, jul./dez. 2011. Disponível em: http://periodicos.uem.br/ojs/index.php/ActaSciHumanSocSci/article/view/12407/ pdf_1. Acesso em: 08 de jul. 2013.

BRASIL. Ministério do Desenvolvimento Social e Combate à Fome. Data Social. [201-]. Disponível em: http://aplicacoes.mds.gov.br/sagi/simulacao/layout/teste/miv_novo. php. Acesso em: 21 ago. 2018.

BRASIL. Ministério do Desenvolvimento Social e Combate à Fome. Norma Operacional Básica NOB/SUAS: construindo as bases para a implantação do Sistema Único de Assistência Social. Brasília, DF, 2005.

CAVALCANTE, P.; RIBEIRO, B. B. O Sistema único de assistência social: resultados da implementação da política nos municípios brasileiros. Revista Administração Pública, Rio de Janeiro, v. 46, n. 6, p. 1459-1477, nov./dez. 2012. Disponível em: http://bibliotecadigital. fgv.br/ojs/index.php/rap/article/view/7131/5677. Acesso em: 8 jul. 2013.

CINGOLANI, L. The state of State capacity: a review of concepts, evidence and measures. [S. l.: s. n.], 2013. (UNU-MERIT Working Paper Series). Disponível em: file:///C:/Users/ edufbaa.Edufba-PC/Downloads/wp2013-053\%20(1).pdf. Acesso em: 21 ago. 2018.

DINIZ, E. Globalização, reforma do Estado e teoria democrática contemporânea. São Paulo em Perspectiva, São Paulo, v. 15, n. 15, p. 13-22, 2001. Disponível em: http://www. scielo.br/pdf/spp/v15n4/10368.pdf. Acesso em: 20 ago. 2018.

GEDDES, B. Politician's dilemma: building state capacity in Latin America. Berkeley, University of California Press, 1994.

INSTITUTO BRASILEIRO DE GEOGRÁFIA E ESTATÍSTICA. Perfil dos municípios brasileiros: gestão pública. Rio de Janeiro, 2005. Disponível em: https://munic.ibge.gov. br/index.php?periodo=\&UF=29\&x=69\&y=7. Acesso em: 21 ago, 2018. 
INSTITUTO BRASILEIRO DE GEOGRÁFIA E ESTATÍsTICA. Perfil dos municípios brasileiros. Rio de Janeiro, 2009. Disponível em: https://munic.ibge.gov.br/index. php?periodo=\&UF=29\&x=69\&y=7. Acesso em: 21 ago, 2018.

MANN, M. The autonomous power of the states: its origins, mechanisms and results. In: HALL, J. A. States in history. New York: Blackwell Pub, 1986.

MARTINS, H. Formação e fragmentação do estado nacional brasileiro no período imperial: a criação da província do Paraná. Acta Scientiarum. Human and Social Sciences, Maringá, v. 30, n. 1, p. 9-16, 2008. Disponível em: http://periodicos.uem.br/ ojs/index.php/ActaSciHumanSocSci/article/viewFile/2977/3303. Acesso em: 8 jul. 2013.

MONERATT, G. L.; SOUZA, R. G. de. Da seguridade social à intersetorialidade: reflexões sobre a integração das políticas sociais no Brasil. Revista Katálysis, Florianópolis, v. 14, n. 1, jan./jun. 2011. Disponível em: http://www.scielo.br/pdf/rk/ v14n1/v14n1a05.pdf. Acesso em: 8 jul. 2013.

MOTA, A. E. S. da. O mito da assistência social: ensaios sobre estado, política e sociedade. São Paulo: Cortez, 2010.

PEREIRA, Cristiane. Assistência social em territórios estigmatizados: um estudo da atuação da Fundação Leão XIII em Vila Ipiranga, Niterói. 2007. 86 f. Dissertação (Mestrado em Serviço Social) - Pontifícia Universidade Católica do Rio de Janeiro, Rio de Janeiro, 2007.

RIZZOTI, M. L. A. O processo de implantação do SUAS: uma reflexão sob a ótica da gestão. Argumentum, Vitória, v. 2, n. 2, p. 174-188, jul./dez. 2010. Disponível em: http://periodicos.ufes.br/argumentum/article/view/951/681. Acesso em: 8 jul. 2013.

SÁTYRO, N. G. D.; CUNHA, E. S. M.; CAMPOS, J. Análise espacial da burocracia da assistência social nos municípios brasileiros: notas para uma reflexão sobre a capacidade de implementação dessa política. Opinião Pública, Campinas, v. 22, n. 2, maio/ago. 2016. Disponível em: http://dx.doi.org/10.1590/1807-01912016222286. Acesso em: 5 set. 2017.

SKOCPOL, T. States and social revolutions: a comparative analysis of France, Russia, and China. New York: Cambridge University Press, 1979.

SKOCPOL, T.; FINEGOLD, K. State capacity and economic intervention in the early New Deal. Political Science Quarterly, [S. l.], v. 97, n. 2, p. 255-278, Summer 1982.

SOUZA, C. Modernização e capacidade do Estado. [S.l.: s.n.], 2010. Relatório de pesquisa do Projeto PIS/BNDES. Mimeografado.

VAITSMAN, J.; ANDRADE, G. R. B. de; FARIAS, L. O. Proteção social no Brasil: o que mudou na assistência social após a Constituição de 1988. Ciência $\&$ Saúde Coletiva, Rio de Janeiro, v. 14, n. 3, p. 731-741, maio/jun. 2009. Disponível em: http://www.scielo. br/pdf/csc/vi4n3/09.pdf. Acesso em: 8 jul. 2013. 